\title{
INTENCIÓN, LENGUAJE Y DEMOCRACIA EN HABERMAS Y SPINOZA
}

\author{
GONZALO RICCI CERNADAS
}

Universidad de Buenos Aires

\begin{abstract}
RESUMEN: El presente trabajo busca realizar una comparación entre las teorías del lenguaje de dos filósofos racionalistas, uno moderno y otro contemporáneo, Habermas y Spinoza respectivamente. Así, se intenta enfatizar que, lejos de ubicarse en ambos extremos de un abismo irreconciliable, ambos pensadores se hallarían en una posición sumamente propincua. De esta manera, el artículo procederá a elucidar las posiciones de Habermas y Spinoza respecto de la intencionalidad, el lenguaje y la democracia. PALABRAS CLAVE: Habermas; Spinoza; intención; lenguaje; democracia.
\end{abstract}

\section{Intention, language and democracy in Habermas and Spinoza}

ABSTRACT: This paper aims to put in contrast two modern and contemporain rationalist philosopher's theories of language: Habermas and Spinoza, respectively. Therefore, it tries to emphasize that, far away from being at ends of the abyss, both thinkers would share a close position. By this way, the article will procede to elucidate Habermas and Spinoza's position in relation to intentionality, language and democracy.

KEY WORD: Habermas; Spinoza; intention; language; democracy.

\section{INTRODUCCIÓN}

Es precisamente en el capítulo IV del primer tomo de la Teoría de la acción comunicativa, intitulado «De Lukács a Adorno: la racionalización como cosificación», donde, exponiendo que la denominada primera Teoría Crítica fracasó debido al agotamiento del paradigma de la filosofía moderna del sujeto, se halla la siguiente declaración de Habermas: «En las categorías de la filosofía de la conciencia, tal como se desarrolla de Descartes a Kant, no se puede dar plausiblemente acomodo a la idea de reconciliación, y en los conceptos del idealismo objetivo, tal como se desarrolla desde Spinoza y Leibniz hasta Schelling y Hegel, sólo puede ser formulada en forma delirante» (Habermas, 2010b: 441). De esta manera, se inscribe a Spinoza en un modelo filosófico de la conciencia, de donde la tan mentada reconciliación de la relación entre el sujeto y el objeto regulada por la razón instrumental no puede tener buen puerto.

Lo que buscamos realizar en el presente trabajo es poner en relación la filosofía de Jürgen Habermas y Baruch Spinoza, versando principalmente sobre el estatuto del lenguaje en el pensamiento de cada uno. Dicha propuesta debe, asimismo, estar informada también de las enormes diferencias en las circunstancias históricas que median entre ambos personajes para no caer en un anacronismo falaz. Aun así, salvando estas ingentes distancias temporales, podemos advertir ciertas características que ejercen como Norte en su pensamiento: ambos se ubican, de una o de otra 
manera, en la senda que determinará la Ilustración: bien se trate de Spinoza, en el marco racionalista temprano moderno, bien se trate de Habermas, ahora ya dentro de una filosofía pragmática-lingüística, donde la razón, o más precisamente, la promesa inaugurada por la razón, hermanada a una labor eminentemente crítica, es la dovela central que guía sus reflexiones sobre la manera de emancipar a los hombres de los prejuicios infundados y de las falsas creencias. A su vez, es menester destacar que ambos autores derivan de estos presupuestos una forma de organización de la comunidad política en términos democráticos.

Por este motivo, es el interés del presente trabajo plantear una serie de problemáticas en las que creemos se manifestarán los puntos de continuidad y de divergencia entre los dos autores elegidos, tomando en cuenta el basamento común mencionado en el párrafo anterior. Así, tomaremos como punto de partida la crítica realizada por Habermas a la teoría de la intención para compararla con la concepción spinoziana de la voluntad [1], para luego analizar la apreciación del lenguaje en la teoría de cada uno [2], y así finalizar con las respectivas consideraciones de la democracia explícitas [3].

\section{CRÍtica de La INTENCIÓN}

El esfuerzo de Habermas por hacer de la teoría de la acción comunicativa «el principio de una teoría de la sociedad que se esfuerza por dar razón de los cánones críticos de los que hace uso» (Habermas, 2010b: 15) significa precisamente un alejamiento de aquella posición defendida por él con anterioridad, esto es, la renuncia a construir una teoría de la sociedad a través de una crítica radical de la teoría del conocimiento (cfr. Habermas, 1990). De esta manera, entender la teoría de la acción comunicativa en términos no ya de una metateoría significa un rechazo de cualquier actitud epistemológico-científica objetivante para pasar, en cambio, a concebir el problema del conocimiento como derivado de las estructuras interaccionales del entendimiento, en tanto pragmáticamente basado respecto del trasfondo del mundo de la vida. Realizar, así, esta empresa que se propone dar cuenta de las estructuras comunicativas del mundo de la vida implica necesariamente una crítica a cualquier concepción de la acción social qua modelo intencional. Para elucidar esto es necesario reponer la discusión efectuada por Habermas tanto con Edmund Husserl como con Max Weber.

En el caso de Husserl, se presupone que nos encontramos abandonados a una plétora de pretensiones de validez que inhieren un tipo determinado de legitimidad, es decir, estamos expuestos a estructuras de sentido que operan fácticamente, a las que Husserl intenta aprehender bajo el concepto de intencionalidad de raigambre brentaniana: esto es, vivencias intencionales dirigidas a algo, orientadas a un objeto o a un estado de cosas. En cualquier caso, como Habermas reconoce, es el mérito de Husserl «haber aclarado la estructura intencional de nuestra conciencia y el haber mostrado la inmanente referencia que las vivencias intencionales hacen a la verdad» (Habermas, 1997: 42). Así, la verdad, tal como Husserl la dilucida, se define en relación al concepto de intencionalidad, puesto que ella sería la coincidencia identificadora entre aquello pretendido por nuestra intención 
y el objeto intuitivamente dado: de modo que los aparentes insumos virtuosos de la fenomenología husserliana a la teoría del conocimiento (a saber, su teorización sobre el mundo de la vida y el giro descriptivo de los objetos dados en él) quedan apresados por una filosofía de la conciencia que obliga a introducir toda fundamentación intersubjetiva «de contrabando» (Habermas, 1997: 54). En efecto, tanto en las apresentaciones, que son descritas por Husserl como discurriendo en forma concordante, como en su yo fenomenológico que reduce todo horizonte posible de acreditación a su propia subjetividad, se encuentra ínsito el trasfondo de la filosofía de la conciencia que, partiendo de una reflexión subjetiva solitaria, excluye que los demás puedan guardar con uno mismo la misma relación que uno guarda con ellos como objetos intencionales.

Weber, por su parte, también estaría atado a una teoría intencionalista de la conciencia que le impide formular la acción social como comunicativa y orientada al entendimiento. Esto es, en el modelo weberiano la explicación del sentido de la acción remite en forma inmediata a una concepción eminentemente nomológica: los sujetos aparecerían, así, actuando teleológicamente unos sobre otros, orientados al éxito, sin dejar margen alguno para juzgar racionalmente las acciones de otra manera que no sea con arreglo a fines. El peso del modelo teleológico que otorga carta de ciudadanía únicamente a la racionalidad medio-fin ocupa un lugar tal en los desarrollos teóricos de Weber que bloquea cualquier intento de explicación de una acción orientada al entendimiento, producto de esta «estrechez monológica» (Gil Martín: 2003: 221): «Weber no establece con claridad suficiente, en el plano de las orientaciones mismas de la acción, esta interesante distinción entre relaciones sociales que vienen mediadas por una trama de intereses y las que vienen mediadas por un acuerdo normativo» (Habermas, 2010b: 329). Vemos ya perfilarse la apuesta habermasiana, que rehúsa reducir el modelo de acción racional al arreglo a fines, puesto que éste presupone que el actor busca alcanzar una meta precisa según fines concretos, eligiendo los medios más adecuados en función del contexto y considerando a las consecuencias derivadas como condiciones colaterales del éxito logrado.

Precisamente, Habermas combate estas conceptualizaciones que conciben al entendimiento como un fenómeno derivado de un sentido de la acción, subjetivo, teleológico y precomunicativo: «Elegir la intencionalidad como un punto de partida del análisis filosófico parece llevar necesariamente a una concepción sub-socializada de nuestra cognición y agencia» (Schmid, 2009: 155). Para una teoría de la acción comunicativa, antes bien, importa la estructura de la expresión lingüística y no la intención del lenguaje, lo que habilita entonces comprender que los planes de acción de los actores se coordinan mediante actos de entendimiento al mismo tiempo que forman una red que cubre el espacio social y el tiempo histórico. Este modelo de la acción comunicativa permite entonces dar cuenta de la relación inmanente entre el lenguaje y el entendimiento, y, por sobretodo, muestra la importancia de considerar que los participantes, si bien persiguen sus fines individuales, lo hacen bajo la sola condición de que sus respectivos planes puedan armonizarse entre sí so definición compartida de la situación.

En Spinoza, por su parte, la crítica a la teoría de la intención es asaz interesante. El sistema ontológico spinoziano es necesarista (cfr. Garret, 1991), esto es, tal como fue definida una de las propiedades de Dios en el segundo corolario de la proposición 16 de la primera parte de la Ética, «Dios es causa por sí y no por accidente», es 
decir, Dios es causa necesaria, cuya causalidad es la expresión global de la necesidad divina que, disponiendo del mayor grado de realidad, afirma su propio ser y la realidad de todas las cosas que de ella se desprenden. Si aparte de Dios no se puede concebir ninguna sustancia, tendremos que entender que esto que se desprende de él son los modos o afecciones de la sustancia, subsidiarios ontológica y gnoseológicament. Estos modos, por mor de la inmanencia de la filosofía spinoziana, no son ajenos a la sustancia divina que permanece y no transita respecto de ellas, sino que desarrolla toda su razón de sí excluyendo cualquier posibilidad de modificación o alteración. Es en este sentido que puede decirse que «una cosa se llama necesaria o por razón de su esencia o por razón de su causa[, por lo que] la existencia de una cosa se sigue necesariamente o bien de su misma esencia y definición o bien de una causa eficiente dada» (Spinoza, 2000: 64). Dicho de otro modo, las cosas no existen $\mathrm{u}$ operan por virtud de su propia naturaleza, sino que lo hacen gracias a la naturaleza divina. Este carácter necesario del sistema es tal debido a la completa identidad entre la naturaleza naturante y la naturaleza naturada, que permite, de esta manera, trasferir los principios y causalidades divinas a todas las consecuencias de su acción.

Sin entrar en mayores detalles, podemos ver que el énfasis en este carácter necesario tiene algunas virtudes. Gracias a la proposición 7 de la segunda parte, por la cual se afirma que «el orden y la conexión de las ideas es el mismo que el orden y la conexión de las cosas», es posible vislumbrar que este mismo orden de necesariedad causal es tan imputable tanto hacia lo que acontece en el atributo pensamiento como en el de la extensión: este es el basamento de aquello que ya se perfiló en la demostración de la proposición 11 en la primera parte, el principio de causa seu ratio, o la reversibilidad absoluta entre la explicación (del orden del pensamiento) y la producción (del orden de la extensión). Como decíamos recién, esta necesariedad permite, así, negar cualquier carácter incondicionado que pueda atribuírsele a la voluntad, ya que ésta se rige por las mismas leyes deterministas que valen para toda la naturaleza naturada. La volición, así, apenas un cierto modo de pensar, no es de ninguna manera una causa libre, sino que «necesita, como todas las demás cosas, una causa por la que sea determinada a existir y a obrar de cierto modo» (Spinoza, 2000: 63), es decir, determinada a obrar por otra, y así al infinito. De la misma manera que sucede con el movimiento el reposo en el plano de la extensión, la voluntad se rige por el mismo principio de necesidad que responde a un concatenamiento infinito de causas.

Con ello puede entonces Spinoza emprender la crítica a los hombres que se consideran libres (tal como es definido el término en la séptima definición de la parte I de la Ética), puesto que ignoran las causas que los determinan a obrar. Así, los hombres piensan que ejercen una prerrogativa absoluta sobre su entorno al reducir todo deseo propio o intención a una voluntad absoluta que todo lo puede, y que de la misma manera hace instalar una consideración utilitaria respecto de las cosas que los rodean. Este es el tan mentado prejuicio finalista, por el cual los hombres toman a los efectos por causas, que deriva finalmente en que consideren a las cosas naturales como meros medios para satisfacer sus deseos. Esta creencia, según la denuncia del filósofo holandés, es un delirio, nacida de la verdadera ignorancia de estos hombres que se imaginan a sí mismos como un imperio dentro de otro imperio. Rechazando cualquier noción de voluntad como absoluta o libre, pues la misma «no puede ser causa libre de sus acciones» (Spinoza, 2000: 114), Spinoza la 
resignifica de manera que refiere a la facultad de afirmar y negar, facultad que no puede ser concebida sin la idea a la cual alude, con lo que a la postre se produce una equiparación entre voluntad y entendimiento ${ }^{1}$.

En el mismo tono de la disquisición realizada sobre la voluntad debe entenderse el descentramiento de la conciencia operado por Spinoza. Puesto que el alma no tiene conocimiento de los cuerpos que la rodean y de su propio cuerpo más que a través de las diversas afecciones recibidas, puede entonces postularse que el propio conocimiento del alma, o su «conciencia es, así, indirecta» (Macherey, 1998: 98), en la medida que surge mediada por las ideas de las afecciones corporales. Ahora bien, de la misma manera que podemos hablar del alma como idea del cuerpo, también podemos hablar de la idea del alma, es decir, la idea de aquella idea (del cuerpo). Aquí radica la clave para explicar, aún más, qué es la conciencia de sí (o autoconciencia): es recién a partir del doble paralelismo intra-cogitativo habilitado por la distinción entre la idea y la idea de la idea que se permite establecer entonces una teoría de la certeza, es decir, saber que se sabe y no dudar de ello.

Esto es lo particular de la génesis de la conciencia en Spinoza, y por ello cabe inclusive referirse a ella como "una suerte de reflexibilidad sin reflexibilidad, o, si queremos decir, una conciencia sin conciencia» (Macherey, 1997: 196-197). De igual modo, si acaso también cabe postular la existencia de una teoría de la intención en Spinoza (cfr. Lenz, 2012: 29-58), sólo podría admitirse bajo la condición de no considerarla como un efecto de una conciencia con prerrogativa absoluta, sino que se encuentra en relación con la doctrina del conato, la cual se reduce al esfuerzo de perseverar en su ser, la tendencia natural de la existencia individual hacia la actividad, alejada de una interpretación utilitarista. Es así que Étienne Balibar puede afirmar que «en la teoría de Spinoza, "conciencia” no es sino la diferencia (modal) entre apetito y deseo»(Balibar, 2009: 12). A lo sumo, la conciencia acompaña las manifestaciones mentales del conatus, pero "en manera alguna constituye su condición o lo precede, pues éste tiene la forma de un impulso y no de una intención que se apoyaría sobre una representación pre-elaborada de su fin y proyectándose concientemente hacia él: es el impulso [élan] espontáneo del conatus que explica la conciencia y no a la inversa» (Macherey, 1998: 96).

\section{El Lenguaje}

Prácticamente puede replicarse la misma impugnación de Habermas a la teoría de la acción intencionalista respecto a la semántica intencional. De acuerdo con esta corriente, el significado de una emisión se refiere a la intención propulsada por el hablante, por lo que enunciado e intención se demuestran evidentemente anejos entre sí. A diferencia de lo postulado por Paul Grice, el modelo intencionalista no se sitúa en el plano del entendimiento, porque, antes bien, "parte de una situación en que, a causa de la imposibilidad de entendimiento directo, (...) la comunicación ha de conseguirse por medio de un comportamiento estratégico, quedando en

1 Para ver cómo, después de esta crítica, queda redefinida la noción de voluntad, cfr. JAQUET (2007: 13-31). 
suspenso el presupuesto de que el hablante manifiesta verazmente sus intenciones» (Habermas, 1997: 288). En este sentido, Austin también queda preso de este paradigma, no por cuanto los actos de habla perlocucionarios implican un objetivo por parte del hablante, una acción orientada a un fin para intervenir en el mundo objetivo, sino principalmente por «no distinguir estos dos casos [actos con fines ilocucionarios y actos con fines perlocucionarios] como tipos distintos de interacción porque se inclinaba a identificar los actos del habla, es decir, los actos del entendimiento, con las propias interacciones mediadas lingüísticamente» (Habermas, 2010b: 340). No sólo porque Austin habría fallado en desligar los actos de habla de los contextos tanto de acción comunicativa como de interacción estratégica, sino porque también portaría cierto resabio veritativo al ligar la fuerza ilocucionaria a una convención contextual, definiendo así «el papel ilocucionario como una fuerza irracional» (Habermas, 2010b: 323)2.

¿En qué sentido específico se relaciona esta crítica del intencionalismo con el lenguaje? Parapetándonos en la distinción de los tres mundos (objetivo, subjetivo y social) (cfr. Habermas, 2010b: 136), podemos decir que una acción teleológica, que busca intervenir en el mundo objetivo (entendido como conjunto de entidades respecto de las cuales es pasible de formular enunciados verdaderos), subtiende una concepción del lenguaje como despotencializado (cfr. Pérez, 2011), al introducir condiciones estratégicas externas al lenguaje, y paralizando su potencial de coordinar acciones. Retomando lo esbozado en el párrafo anterior, se evidencia la ligazón entre este tan mentado intencionalismo y los efectos perlocucionarios, puesto que en éstos los actos del habla son instrumentalizados con el objeto de concretar un propósito determinado en el mundo, guardando con lo dicho una relación de mera contingencia. Por ello el presupuesto de veracidad de los hablantes queda minado si nos referimos a las perlocuciones, porque «un hablante que actúa teleológicamente tiene que conseguir su propósito ilocucionario de que el oyente entienda lo dicho y contraiga las obligaciones involucradas en la aceptación de la oferta que el acto de habla contiene, sin dejar traslucir su propósito perlocucionario. Esta reserva es lo que presta a las perlocuciones su carácter peculiarmente asimétrico de acciones estratégicas encubiertas» (Habermas, 2010b: 339). Al contrario, en la acción comunicativa, los participantes armonizan sus planes de acción individuales persiguiendo sus fines ilocucionarios sin reserva alguna.

En este sentido se cifra la diferencia atizada por Habermas entre actuar y hablar: la semántica intencionalista no es capaz, en el sentido de su teoría del significado, de distinguir entre el aspecto verbal y no verbal de la acción (puesto que considera la emisión como medio que indica el fin del hablante), y precisamente esta carencia de discernimiento le impide, de esta manera, determinar la dimensión propia del medio lingüístico en la producción y el reconocimiento del significado. Hablar es cosa bien distinta: refiere necesariamente al entendimiento y, a su

2 De ahí el énfasis de Cristina Lafont en las siguientes características del uso comunicativo del lenguaje: «dicha acción está ligada al reconocimiento de las pretensiones de validez que los participantes de la acción entablan en sus efectos perlocucionarios, como que "tal reconocimiento no necesita ser irracional porque las pretensiones de validez tienen un carácter cognoscitivo y son susceptibles de someterse a examen”»(LAFOnT, 1993: 155). 
vez, las condiciones de racionalidad de la acción comunicativa en cierto sentido trascienden al mundo en su vertiente objetiva (como así también social y subjetiva).

"Oponiéndose a la "filosofía del sujeto" Habermas está interesado en dar cuenta de la acción (y significado) entendidas no bajo un modelo particular de intencionalidad (...) sino que comienza con el reconocimiento intersubjetivo (vía una práctica de adscripción mutua) de ego y alter como "dadores de razón" "(Baynes, 2015: 148). El modelo comunicativo de la acción se aleja tanto de la producción de efectos perlocucionarios, como del establecimiento de relaciones interpersonales y/o la expresión de vivencias. La acción comunicativa se encuentra orientada al entendimiento, mediante un proceso que tiene por telón de fondo de preconcepción y en el cual nos encontramos ya inscriptos por mor de la propia pertenencia cultural; de manera que en los actos de entendimiento de la acción comunicativa los hablantes integran los mentados tres mundos que anteriormente aparecían en forma solitaria. Así, los hablantes relativizan sus manifestaciones puesto que la validez de las mismas pueden ser cuestionadas por otros actores. Parando mientes en la distinción realizada entre actuar y hablar, el entendimiento permite la coordinación de acciones mediante el reconocimiento intersubjetivo de las pretensiones de validez que manifiestan unos a otros: es decir, los procesos cooperativos de interpretación dejan entrever que la acción comunicativa no se agota en el acto de entendimiento, ya que justamente esta acción refiere a un tipo de interacciones que vienen coordinadas a través de actos de habla, pero que no coinciden con ellos. A esto se refiere cuando Habermas postula una «teoría consensual de la verdad» (Habermas, 1997: 113-158), donde la verdad es entendida como una propiedad de los enunciados, siendo verdaderos aquellos enunciados pasibles de ser fundamentados, en donde pueda ser aclarado el significado de la resolución discursiva de las pretensiones de validez. Esta autorreflexión del sujeto cognoscente es postulada sobre la base de una «anticipación de una situación ideal del habla» (Habermas, 1997: 155) que garantiza la asociación entre un consenso logrado fácticamente y la pretensión de un consenso racional. Sólo de esta manera es lícito referirse a una actitud realizativa adoptada por un hablante que busca entenderse con un destinatario. Pero este modelo ideal, que permite hacer extensivo la sociación en términos de teoría democrática, será explicado en el apartado próximo.

Vemos entonces que la concepción que Spinoza tiene del lenguaje coincide en ciertos puntos con el anti-intencionalismo que anima la empresa de Habermas. Pero primero aclaremos lo siguiente: la caracterización spinoziana del lenguaje se encuentra propincua a la de la memoria. ¿En qué sentido? La memoria es el resultado de la concatenación de las ideas de cosas que se encuentran fuera del cuerpo humano, esto es, ideas de afecciones temporal y espacialmente determinadas, por las cuales el alma asocia distintos pensamientos de objetos que no tienen semejanza entre sí. Hay, en ese sentido, un mecanismo de asociación, espontáneo, circunstancial, ocasional, que establece una relación entre objetos que nos han afectado en un espacio y tiempo circunscripto. Pero decíamos que la vinculación entre la memoria y el lenguaje es estrecha: pues el mecanismo de significación de un objeto tiene su basamento en el hábito o costumbre por el cual se asocia la idea de un sonido con la idea de un objeto: de allí nace la palabra. Si cabe hablar del significado de las palabras, deberíamos entonces decir que el mismo surge en virtud de que una palabra fue pronunciada reiteradas veces en presencia de un objeto determinado. A 
través de esta explicación que devela la génesis del lenguaje es que Macherey afirma que «son así sentadas las bases de eso que hoy día llamaríamos una filosofía del lenguaje» (Macherey, 1997: 366).

Así, no se trata tanto de enfatizar el hecho de que por el mecanismo del hábito «nuestra potencia, que no tiene en sí misma ni fin ni objeto, se encuentra atrapada, según sus modificaciones, en un modo de proyectarse en el mundo, en un destino» (Bove, 2014: 54), como de señalar que las palabras evocan imágenes eminentemente confusas y que no responden a un encadenamiento lógico, ligando al lenguaje a lo que Spinoza denomina como primer género de conocimiento. El lenguaje pertenece así al conocimiento imaginativo, asociativo, memorístivo y subjetivo, el terreno de la experientia vaga.

A partir de esta última consideración se establece un clivaje entre los comentaristas de Spinoza. Por un lado, unos resaltan la faz negativa de la concepción spinoziana del lenguaje, en tanto permanente fruto de errores y equívocos, minando, en última instancia, cualquier tentativa dilucidada por el holandés en la escritura y subsiguiente difusión de su proyecto ético-filosófico. En esta línea, David Savan arguye que «la consideración de Spinoza sobre las palabras y el lenguaje hace imposible para él sostener que sus escritos (o los de cualquiera) puedan ser una exposición directa o literal de la verdad filosófica» (Savan, 1973: 60), siendo Spinoza incluso conciente de esta dificultad. Marcelo Dascal acuerda con este punto de vista, aseverando el abismo infranqueable entre lenguaje y pensamiento, al ser «el cuerpo y el alma dos dominios esencialmente distintos entre sí» (Dascal 1977: 228). Subyace a estas concepciones entonces la incapacidad de expresar una idea adecuada mediante el lenguaje, siendo que sólo es posible obtener un concepto claro a través de la reflexión solitaria del entendimiento (cfr. Jongeneelen, 2001).

A diferencia de las posturas anteriores, no buscamos ubicarnos en el nivel del lenguaje filosófico, sino estudiar la problemática del lenguaje en el nivel vulgar, esto es, en su uso práctico y cotidiano. En pos de esto creemos que, en lugar de enfatizar el componente negativo de un lenguaje innegablemente imaginativo, es menester recordar los dichos de Spinoza respecto de la imaginación, menos para naturalizarla, siendo que «el alma no yerra por imaginar» (Spinoza, 2000: 95), como para poner en evidencia que «se atribuye esta potencia de imaginar a una virtud de la naturaleza del alma» (Spinoza, 2000: 95. Cursivas nuestras). Al hacer esto, nuestra intención no es destacar las posibilidades que habilitan postular un uso estratégico-crítico del lenguaje (Bove, 1991), una intención revolucionaria ínsita a la semántica spinoziana (Walther, 1985), y aún menos de la pretensión de impulsar un lenguaje geometrizado (Hampshire, 1982). Al explicitar esta posibilidad de la imaginación de ser encauzada en los límites del entendimiento, destruyendo así la concepción de la imaginación y el entendimiento como continentes separados, abrimos el horizonte para concebir que el lenguaje pueda ser un medio adecuado para el entendimiento y el conocimiento. El entendimiento debe operar necesariamente con ideas imaginativas, en tanto que es su única fuente de conocimiento, lo que permite vislumbrar «una operación del entendimiento que le asigna un orden lógico a las ideas dadas a través de la imaginación, admitiéndose la posibilidad de que el entendimiento asigne un nuevo significado a los términos del lenguaje natural» (Narváez, 2010: 64), «de resignificar y de repensar las palabras» (Fernández García, 2008: 2010). Si las nociones comunes, aquello común a las partes y al 
todo, pueden ser entendidas en términos lingüísticos, puesto que estas «expresan las ideas adecuadas en el lenguaje»(Baltas, 2012: 155), quizás pueda encontrarse allí el índice de una tentativa de respuesta, permitiendo captar la concurrencia del necesario orden de la naturaleza. Sólo de esta manera, a través de este esfuerzo de la razón, de ninguna manera voluntarista ni motivado intencionalmente, e incluso reducido a la biografía de un hombre particular, sino ubicado en un plano transindividual —o si se quiere, en este sentido, intersubjetivo—, será posible explicar que «la mayor parte de los errores sólo consiste en que no aplicamos correctamente los nombres a las cosas» (Spinoza, 2000: 113), de forma que puedan cerciorarse respecto de qué piensan y pudiendo dar razones concretas en pos entenderse, de modo de diluir los errores y absurdos que abundan, dilucidándose, comprendiéndose, y dejando de enunciar sordamente "palabras sobre palabras, palabras signos de la violencia de lo simbólico» (Abdo Ferez, 2007: 213).

\section{DemOCRACIA}

En la exposición de Habermas se ha hecho explícita la relación estrecha de la noción de racionalidad comunicativa en la estructura de habla humana en general, que, a su vez, designa una relación específica de reconocimiento mutuo entre diferentes individuos. Es sólo a partir de esta consideración que Habermas puede reinterpretar «la idea de Marx de una libre asociación de los productores (...) como la idea de un mundo vital completamente racionalizado» (Wellmer, 1988: 97). Precisamente, la racionalización comunicativa sirve de clave para interpretar el proceso de acción comunicativa como el mecanismo elemental para el consenso y la coordinación de las acciones. Así, esta idea de un mundo vital completamente racionalizado ciertamente acarrea una perspectiva utópica determinada, por lo cual no puede responder por sí sola a la pregunta por la institucionalización de la libertad en una sociedad post-capitalista. Para poder pensar esto es necesario realizar dentro de la noción de racionalidad comunicativa «una distinción categorial entre la idea reguladora de un mundo vital completamente racionalizado, por una parte, y los principios organizativos, por otro, que expresarían las estructuras institucionales de las sociedades comunicativamente racionalizadas en un momento dado de la historia» (Wellmer, 1988: 98).

Para explicitar esta distinción analítica trazada por Albercht Wellmer, partiremos primero por elucidar el menado mundo vital racionalizado. Siempre se trata de evitar el contenido ideal de los presupuestos generales de la comunicación, aun cuando digamos que «los participantes en la argumentación parten de la suposición idealizadora de una comunidad de comunicación deslimitada en el espacio social y en el tiempo histórico, y que no tiene más remedio que presuponer dentro de su situación social ideal» (Habermas, 2010a: 400-401). Partiendo de aquello ya explicado en los apartados anteriores respecto de la racionalidad comunicativa, esto es, que el entendimiento entre sujetos se mide por pretensiones de validez susceptibles de ser criticadas a la vez que manteniendo abierta la posibilidad de una resolución discursiva, la «comunidad ideal de comunicación» se ofrece como un modelo de asociación comunicativa pura, es decir, una sociedad que sólo dispone 
del medio del entendimiento discursivo como mecanismo de autoorganización, permitiendo así resolver todos los conflictos y disputas sin violencia mediante. Se trata de sociedades ubicadas tempo-espacialmente, donde se tienen en cuenta las normas heredadas por la costumbre y donde no se hace abstracción de que los actores finitos no disponen de un know how completo de antemano, sino que deben nutrirse de sus recursos del mundo de la vida que no disponen a su voluntad. Ahora bien, este modelo funciona como trasfondo sobre los que se destacan los recursos funcionalmente necesarios para los procesos de entendimiento. Se puede dar cuenta de los costos de información y decisión de procesos de comunicación cuando se enlaza este modelo con una teoría de sistemas y de toma de decisiones.

Esto nos permite dar pie para formular una teoría de la democracia en clave procedimental. En este sentido, la dovela central del proceso democrático la constituye «el procedimiento que representa la política deliberativa» (Habermas, 2010a: 372): la política deliberativa depende de «la institucionalización de los procedimientos correspondientes» (Habermas, 2005: 6). Un concepto de procedimiento de deliberación y de toma de decisiones vinculado a una teoría del discurso habilita no disociar las consideraciones pragmáticas, los discursos de autoentendimiento y los discursos referidos a la justicia al postular que puede arribarse a resultados racionales cuando haya un suministro de información suficiente referida a los problemas. Así, alejada tanto de una concepción liberal de derechos humanos universales como de una republicana eticidad concreta de una comunidad, la razón práctica se asienta en las reglas del discurso y formas de argumentación basadas en la acción orientada al entendimiento. Así, una teoría del discurso hace depender la opinión y voluntad política de «la institucionalización de los correspondientes procedimientos y presupuestos comunicativos, así como de la interacción de deliberaciones intitucionalizadas con opiniones públicas desarrolladas informalmente» (Habermas, 2010a: 374). La imagen de una sociedad descentrada emerge producto de la procedimentalización de la soberanía popular y la vinculación retroalimentativa del sistema político con los espacios públicos políticos. No un todo social centrado ora en el Estado ora en un sistema de normas constitucionales, como así tampoco un actor social colectivo ni actores individuales, se trata más bien de una intersubjetividad de orden superior de los procesos de entendimiento efectuados a través de los procedimientos democráticos o en la red de comunicación de los espacios públicos políticos. Así, la sociedad civil se distingue tanto del sistema económico como del administrativo, posibilitando que la solidaridad ya no se extraiga solamente de la acción comunicativa sino que pueda desarrollarse a través de espacios autónomos y diversos y mediante procedimientos democráticos de la formación de la opinión y voluntad, de manera que por medio del término institucionalizado del Estado de derecho pueda afirmarse una fuerza socio-integradora que no se confunda con el dinero y el poder administrativo. El sistema político, en tanto subsistema especializado, puede mandar, puede tomar decisiones colectivamente vinculantes, mientras que la opinión pública puede dirigir el uso de poder administrativo, percibiendo e identificando las situaciones problemáticas que afectan a la sociedad global. La soberanía popular queda reinterpretada intersubjetivamente, lo que, a su vez, hace que ese self de la comunidad jurídica se disuelva en las formas de comunicación. Así definida, la soberanía popular «remite a las condiciones sociales marco que posibilitan la autoorganización de una comunidad jurídica, pero que por su parte no 
están más a disposición de la voluntad de los ciudadanos» (Habermas, 2010a, 378). Sólo a través de esta manera es posible el mencionado modelo de sociación comunicativa pura en una forma de comunidad jurídica que se organiza a sí misma, sin olvidar nunca que ese modo de sociación discursiva puede efectuarse por medio del derecho, que permite la reducción de la complejidad social.

Insistimos en la importancia de rehabilitar el estatus del lenguaje en la filosofía spinoziana. En tanto que buscan comprender el entorno que los rodea, los hombres buscan explicar las cosas a partir de sus causas. Este esfuerzo racional, así, no puede efectuarse aisladamente, al mismo tiempo que implica un esfuerzo por seleccionar aquellos afectos que se componen favorablemente con nosotros, esto es, que aumentan nuestra potencia y nuestra capacidad por comprender: a ello apuntan las nociones comunes, en tanto representan algo común a los cuerpos. El lenguaje no escapa a esta operación racional íntimamente ligada a ese impulso que es el conato: se trata de eliminar la discordia que surge producto de atribuir distintos significados a las palabras, por lo que el esfuerzo de la razón radica en hallar esas nociones comunes en el lenguaje, comunes tanto a las partes como al todo. Si hay algo así como un cambio de significación en las palabras de manera que los hombres puedan entenderse entre ellos, adjudicándose un mismo sentido entre sí, ese trastocamiento es en absoluto individual sino colectivo. Entenderse, en ese sentido, es asimismo poder explicar el orden de producción de estos cuerpos que son las palabras, arguyendo así los motivos y las razones concretas por las cuales se actúa. Así comienza el trabajo para aunar afecciones alegres que puedan derivar en alegrías activas.

En este marco, la teoría del conatus es la clave para comprender el régimen democrático que Spinoza propugna. Entender que la libertad de cualquier ser depende del hecho de ser causa adecuada de sus acciones, esto es, obrando por su propia naturaleza y no por una causa externa, aquí vemos operar ese impulso que es el conatus que explicita ese esfuerzo por perseverar en su ser de cada cosa. La libertad entonces se identifica con el aumento de la propia potencia, la participación intensa con el orden de la naturaleza: en definitiva, la propia actividad es entendida como la capacidad de acción racional, «la compresión de la existencia del hombre como una expresión singular implicada en la totalidad de la cual participa, y en la sujeción a esas leyes» (Volco, 2004: 164). Si entrar en un estado civil produce una cierta alienación, esto es producto entonces de la organización de un poder colectivo que permita afectar a los hombres de manera que éstos obedezcan las leyes, permitiendo regular la situación pasional a las que los hombres se encuentran siempre expuestos. En el estado civil, así, se hace posible una existencia común más estable y pacífica. El régimen democrático, en este sentido, propicia las condiciones más favorables para una existencia libre en tanto da lugar para coadyuvar a la potencia individual y la potencia colectiva, sin ser indiferente a la naturaleza necesariamente pasional del hombre al universalizar la causa de miedo y esperanza

De aquí proviene la defensa realizada por Spinoza en el Tratado teológico-politico de la libertad de expresión. Como más tarde afirmará en el Tratado político: «si mientras los romanos deliberan, se pierde Sagunto, al revés, mientras unos pocos lo deciden todo según su gusto, perecen la libertad y el bien común. Porque los talentos humanos son demasiado cortos para poder comprenderlo todo al instante. Por el contrario, se agudizan consultando, escuchando y discutiendo, y a fuerza de ensayar todos los medios, dan finalmente, con lo que buscan» (Spinoza, 2010: 
230). Se hace evidente ya que «la subjetividad de las ideas generales (universales y trascendentales) se convierte en un obstáculo infranqueable para la comunicación» (Narváez, 2009: 101): es necesario que los hombres hablen y deliberen entre sí. Es por ello que la propuesta democrática de Spinoza consiste en multiplicar los consejos, puesto que si el pueblo «es capaz de moderación y juicio correcto, entonces merece gobernar en lugar de ser gobernado» (Chaui, 2003: 432). Pero lo que merece ser destacado es el hecho de que «la libre discusión no nace a causa de ideas verdaderas, sino que las engendra. (...) La discusión, si no da lugar para propiamente hablar las ideas, permite apartar los obstáculos a su desarrollo» (Moreau, 2012: 376). Esta es precisamente la característica benéfica o virtuosa de la discusión, en tanto las palabras pueden ser portadoras de ideas adecuadas o útiles puesto que ayudan a fijar las ideas. Por eso Balibar puede decir que la práctica comunicativa -o, en palabras de Pierre-François Moreau, esa «pulsión de hablar» (2012: 370)—, tal como la describe Spinoza, representa «un esfuerzo de los individuos por provocar la razón, representándose su necesidad, las acciones a las cuales éstos están muy a menudo determinados por sus pasiones» (Balibar, 2011: 112). Así, este esfuerzo puede traducirse en una teoría del régimen democrático que no queda librado únicamente a la pura potencia de la multitud que permanentemente emplea distintas modalidades de comunicación, sino que esta libertad de opinión se enhebra y estabiliza por medio de «instituciones que deben generar las condiciones para la mayor diversidad posible de opinión, de manera que las decisiones que tomen puedan basarse efectivamente en la combinación de todos los puntos de vista existentes» (Balibar, 2011: 139), permitiendo entonces no sólo publicitar los problemas que atañen al vivir en comunidad sino habilitar también a los ciudadanos para ejercer sus juicios en los asuntos públicos.

\section{CONCLUSIÓN}

Hemos comenzado el presente trabajo poniendo en liza un elemento que nos parecía común y que animaba las principales críticas tanto del pensamiento de Habermas como de Spinoza. Para el filósofo alemán es asunto decisivo someter a una impugnación radical a la teoría de la intención (que hemos ejemplificado a través de Husserl y Weber), puesto que esta es la clave para dar el mentís a aquellas filosofías que pretendían fundar (o que al menos podían dar elementos para hacerlo) una concepción de la sociedad (de donde incluso podía emanar una ética) en términos intersubjetivos. Tales intentos resultaban, así, fútiles y vanos al tener que presuponer esta intersubjetividad desde un comienzo, ya dada, resultando, en verdad, indudablemente atada a un intencionalismo que a veces daba pie a un comportamiento instrumental-estratégico. En Spinoza, por su parte, también se atisba una refutación a la voluntad del hombre como prerrogativa absoluta amparándose en el carácter necesario y determinista del mundo³ , pero, principalmente, revelándola

3 En este sentido podría llegar a aducirse que la filosofía de Spinoza tiene una arista mecanicista, puesto que ubica a la voluntad no como una causa libre, sino como un efecto de la concatenación de causas que la ha producido. Así, la posición de Spinoza quedaría 
como producto de un estado de ignorancia al afirmar que, antes bien, el individuo no comanda sus deseos a piacere sino que el deseo surge producto de un impulso más primario que tiende a la preservación del ser propio del hombre, el conatus, del que la propia conciencia es también subsidiaria. Lo original, en este sentido, del planteo spinoziano nos lleva entonces a redefinir la noción de conciencia en términos no intencionalistas ni utilitarios, alejada así de las críticas habermasianas

No nos detendremos en las problemáticas de enlazar la voluntad y la conciencia a este conato que parecería tener cierta arista vitalista, sino que lo que buscamos es continuar a fin de demostrar que esta crítica realizada al intencionalismo por el alemán y el holandés permean en sus conceptualizaciones del lenguaje. En Habermas, paralelamente a lo descripto en el párrafo anterior, la impugnación se traslada a la semántica intencionalista que se encuentra hermanada a un énfasis en los efectos perlocucionarios del lenguaje que pone en jaque el presupuesto de veracidad que los hablantes deberían tener entre sí con el objeto de emprender, si quisieran, un cuestionamiento de sus pretensiones de validez. En Spinoza, aunque la explicación del lenguaje se encuentra emparejada a la de la memoria, esto es, a eventos temporal y espacialmente situados, encontramos que el lenguaje, no obstante, puede también convertirse en algo digno de elogio al posibilitar el entendimiento entre las personas, un entendimiento comprendido también como extensión de ese esfuerzo que es el conatus, y que tiende a perseverar en el ser en tanto el hombre es más activo en tanto que más racional es, esto es, en tanto que más es causa adecuada y más tiene idea adecuada de las cosas. El hombre entreteje así relaciones con otros hombres por medio del lenguaje, propiciando las ideas adecuadas, superando esa experiencia vaga a la cual se encuentran sometidos bajo el género de conocimiento de la imaginación, propio de la experiencia cotidiana. En este sentido preciso, Habermas parece cercano a este planteo, no sólo en cuanto argumenta que la estabilidad y la univocidad son la excepción en la práctica comunicativa del día a día (Habermas, 2010b: 137), sino también en ese sentido en que él se siente cercano a Popper, en que «podemos aprender de nuestros errores y de la crítica» (Habermas, 1988: 65).

Finalmente, las concepciones de la democracia de ambos autores abrevan fuertemente de sus pareceres respecto del lenguaje. En el caso de Habermas, la «comunidad ideal de comunicación» se ofrece como modelo a ser elaborado en una escala social en términos deliberativos y procedimentales que inhiere así la formación de una opinión pública, la información por parte de los ciudadanos, y su participación en la toma de decisiones de forma institucionalizada en los procedimientos correspondientes. En Spinoza, vemos también que el lenguaje en el régimen político democrático juega un rol crucial en relación a eso que contemporáneamente puede denominarse como opinión pública. La defensa realizada por el filósofo holandés

indefensa a la objeción de que su concepción de mundo — un solo mundo, puesto que es uno que se percibe por medio de atributos distintos- $-\mathrm{y}$, por ende, tanto los cuerpos como las ideas, se encuentran regidas por el modelo de causalidad que Habermas menciona que Popper atribuye a su primer mundo, aquel que consta de objetos o estados físicos (cfr. PoPPER, 2001: 106-146). Prosiguiendo con esta elucidación, otra impugnación posible es que, al haber un solo mundo en Spinoza, no hay resto alguno que pueda ser sometido a esa interpretación que es característica de la acción comunicativa orientada al entendimiento: ese es, en efecto, el rasgo holista de Habermas (Pérez, 2011: 269). 
por los consejos como forma de poner freno a la tiranía evidencia la creencia de que la libre discusión puede derivar en el engendramiento de ideas verdaderas, y, en términos ampliados, favorecer que los ciudadanos se informen e involucren en los asuntos de la comunidad. A su vez, y a diferencia de lo que propugnase Negri (1993; 2015), la multitud no es pura potentia, sino que involucra cierta potestas que, "con todo, afirma esta potencia» (Abdo Ferez, 2013: 222), permitiendo estabilizar ese «impulso de hablar» que los hombres tienen en instituciones políticas en las cuales ellos toman participación en la deliberación y la decisión.

Con este trabajo no hemos buscado establecer a Spinoza como una inspiración intelectual de Habermas, ni mucho menos postular que aquél habría sido un antecesor de éste. Respetando las grandes diferencias temporales que se transmutan en los paradigmas irreconciliables en el que ambos autores se encuentran ubicados, simplemente se ha tratado de explicitar aquellas resonancias que un racionalista como Spinoza parecía tener en un Habermas imbuido en la filosofía pragmáticalingüística. Estos puntos, enumerados en el presente trabajo, parecían muy próximos y compartidos por los autores, aún se trate en su faz formal. Pero de todas maneras, sí ha sido nuestra intención mostrar estos puntos de coincidencia que quizás se expliquen por el hecho de que tanto Spinoza como Habermas confían en esa promesa abierta por la razón para desterrar los prejuicios y abrir un horizonte emancipatorio, coincidencias que, al fin y al cabo, demostrarían que Spinoza no podría ser encasillado tan fácilmente en esa tradición de la filosofía de la conciencia y del idealismo objetivo en la que Habermas lo ubica.

\section{BiBLIOGRAFÍA}

Abdo Ferez, C. (2007). «Historias, experiencia, lenguaje». Spinoza. Tercer coloquio. Córdoba (Argentina): Brujas.

Abdo Ferez, C. (2013). Crimen y sí mismo. Buenos Aires: Gorla.

Balibar, É. (2009). De la individualidad a la transindividualidad. Córdoba (Argentina): Brujas. Balibar, É. (2011). Spinoza y la política. Buenos Aires: Prometeo.

Baltas, A. (2012). Peeling potatoes or grinding lenses. Spinoza and young Wittgenstein converse on immanence and its logic. Pittsburgh: University of Pittsburgh Press.

Baynes, K. (2016). Habermas. Oxfordshire \& New York: Routledge.

Bove, L. (1991). «La théorie du langage chez Spinoza». L'Enseignement philosophique, 4.

Bove, L. (2014). La estrategia del conatus. Buenos Aires: Cruce.

Chaui, M. (2003). Política en Spinoza. Buenos Aires: Gorla.

Dascal, M. (1977). «Spinoza, Pensamento e Linguagem». Revista Latinoamericana de Filosofía, 3.

Fernández García, E. (2008). «Historia de las palabras: la importancia del uso». En Carvajal, J. \& de la Cámara, M. L. Cuenca (coords.). Spinoza: de la física a la historia. Ediciones de la Universidad de CastillaLa Mancha.

Garrett, D. (1991). «Spinoza's necessitarianism». En Yovel, Y. (ed.), Spinoza's metaphysics: papers presented at the first Jerusalem conference (Ethica I). Leiden: E. J. Brill.

Gil Martín, F. J. (2003). «El giro pragmático de Habermas. Tres momentos de su aleación de las concepciones del lenguaje de la hermenéutica y la analítica». Azafea. Revista de filosofía, 5.

Habermas, J. (1988). La lógica de las ciencias sociales. Madrid: Tecnos.

Habermas, J. (1990). Conocimiento e interés. Madrid: Taurus. 
Habermas, J. (1997). Teoría de la acción comunicativa: complementos y estudios previos. Madrid: Cátedra.

Habermas, J. (2005). «Tres modelos de democracias. Sobre el concepto de una política deliberativa». Polis, 10.

Habermas, J. (2010a). Facticidad y validez. Madrid: Trotta.

Habermas, J. (2010b). Teoría de la acción comunicativa. Madrid: Trotta.

Hampshire, S. (1982). Spinoza. Madrid: Alianza.

Jaquet, C. (2007). «El rol positivo de la voluntad en Spinoza». Spinoza. Tercer coloquio. Córdoba (Argentina): Brujas.

Jongeneelen, G. H. (2001). «Semantic Change and the Semantics of Spinozism». Lexicon Philosophicum, 11.

Lafont, C. (2011). La razón como lenguaje. Madrid: Visor.

Lenz, M. (2012). «Intentionality without Objectivity? Spinoza's Theory of Intentionality». En Salice, A. (ed.). Intentionality. Historical and Systematic Perspectives. Munich: Philosophia.

Macherey, P. (1997). Introduction à l'Éthique de Spinoza: La seconde partie - la réalité mentale. Paris: PUF.

Macherey, P. (1998). Introduction à l'Éthique de Spinoza: La troisième partie - la vie affective. Paris: PUF.

Moreau, P.-F. (2012). Spinoza. L'expérience et l'éternité. Paris: PUF.

Narváez, M. (2009). El problema del lenguaje en Spinoza: crítica del lenguaje natural, paralelismo y posibilidad del lenguaje de expresar conocimiento filosófico. Tesis de Grado no publicada, Universidad Nacional de La Plata, Facultad de Humanidades y Ciencias de la Educación, Argentina.

Narváez, M. (2010). «Elementos de la concepción del lenguaje en Spinoza». Revista Conatus, 4.

Negri, T. (1993). La anomalía salvaje. Barcelona: Anthropos.

Negri, T. (2015). El poder constituyente. Madrid: Traficante de sueños.

Parkinson, G. H. R. (1973). «Language and knowledge in Spinoza». En Grene, M. (ed.), Spinoza. A collection of critical essays. New York: Anchor Press/Doubleday.

Pérez, G. (2011). «Hablar, actuar, juzgar: contribuciones de la pragmática a la teoría social contemporánea». En Schuster, F. L. (comp.), Filosofía y métodos de las ciencias sociales. Buenos Aires: Manantial.

Popper, K. (2001). Conocimiento objetivo. Madrid: Tecnos.

Savan, D. (1973). «Spinoza and language». En Grene, M. (ed.), Spinoza. A collection of critical essays. New York: Anchor Press/Doubleday.

Schmid, H. B. (2009). Plural action: essays in philosophy and social science. Basel: Springler.

Spinoza, B. (2000). Ética. Madrid: Trotta.

Spinoza, B. (2010). Tratado político. Madrid: Alianza.

Volco, A. (2004). «Libertad individual y libertad política en Spinoza». En Hilb, C. (comp.), Cuando el pasado ya no alumbra el porvenir. La modernidad política y sus críticos. Buenos Aires: Molino.

Walther, M. (1985). «Die Transformation des Naturrechts in der Rechtsphilosophie Spinozas». Studia Spinozana, 1.

Wellmer, A. (1988). «Razón, utopía y la dialéctica de la Ilustración». Habermas y la modernidad. VV.AA. Madrid: Cátedra.

Universidad de Buenos Aires

Facultad de Ciencias Sociales.

Gonzalo Ricci Cernadas.

goncernadas@gmail.com

[Articulo aprobado para publicación en enero de 2018] 